\title{
Solution-Plasma-Mediated Synthesis of Si Nanoparticles for Anode Material of Lithium-Ion Batteries
}

\author{
Genki Saito $^{1, *(D)}$, Hitoshi Sasaki ${ }^{2}$, Heishichiro Takahashi ${ }^{1,2}$ and Norihito Sakaguchi ${ }^{1}$ \\ 1 Faculty of Engineering, Hokkaido University, Kita 13 Nishi 8, Kitaku, Sapporo 060-8628, Japan; \\ takahash@ufml.caret.hokudai.ac.jp (H.T.); sakaguchi@eng.hokudai.ac.jp (N.S.) \\ 2 Kankyou-Engineering Co., Ltd. Kita 19 Higashi 1, Higashiku, Sapporo 065-0019, Japan; \\ ht-sasaki@kankyou-eng.co.jp \\ * Correspondence: genki@eng.hokudai.ac.jp; Tel.: +81-11-706-6345
}

Received: 8 April 2018; Accepted: 25 April 2018; Published: 27 April 2018

\begin{abstract}
Silicon anodes have attracted considerable attention for their use in lithium-ion batteries because of their extremely high theoretical capacity; however, they are prone to extensive volume expansion during lithiation, which causes disintegration and poor cycling stability. In this article, we use two approaches to address this issue, by reducing the size of the Si particles to nanoscale and incorporating them into a carbon composite to help modulate the volume expansion problems. We improve our previous work on the solution-plasma-mediated synthesis of Si nanoparticles (NPs) by adjusting the electrolyte medium to mild buffer solutions rather than strong acids, successfully generating Si-NPs with $<10 \mathrm{~nm}$ diameters. We then combined these Si-NPs with carbon using MgO-template-assisted sol-gel combustion synthesis, which afforded porous carbon composite materials. Among the preparations, the composite material obtained from the $\mathrm{LiCl}$ $0.2 \mathrm{M}+\mathrm{H}_{3} \mathrm{BO}_{3} 0.15 \mathrm{M}$ solution-based Si-NPs exhibited a high reversible capacity of $537 \mathrm{mAh} / \mathrm{g}$ after 30 discharge/charge cycles at a current rate of $0.5 \mathrm{~A} / \mathrm{g}$. We attribute this increased reversible capacity to the decreased particle size of the Si-NPs. These results clearly show the applicability of this facile and environmentally friendly solution-plasma technique for producing Si-NPs as an anode material for lithium-ion batteries.
\end{abstract}

Keywords: solution plasma; nanoparticles; batteries; silicon; anode materials

\section{Introduction}

Rechargeable lithium-ion batteries (LIBs) have been widely used as energy-storage devices for applications such as portable electronic devices and electric vehicles. Among the newer anode materials with higher capacities, silicon anodes have attracted considerable attention because of their high theoretical capacity of $4200 \mathrm{mAh} \cdot \mathrm{g}^{-1}$, which exceeds that of commercialized graphite anodes [1-4]. During the lithium insertion-extraction process, however, a large volume change $(>280 \%)$ inevitably occurs, which leads to pulverization of the silicon anode and loss of electrical contact with the current collector, resulting in poor cycling performance [2,5]. To mitigate this volume-change issue, several strategies have been proposed, including reducing the particle size to nanoscale [6,7], fabricating Si nanostructures such as nanowires and nanoporous materials [8-11], utilizing hollow core-shell structures [12], and dispersing nano-Si in a conductive carbon matrix to form Si-carbon composites [13-19]. Liu et al. clarified that the critical particle diameter for a Si anode should be less than $150 \mathrm{~nm}$ to avoid surface cracking and subsequent fracturing during lithiation [5]. In addition, dispersing silicon nanoparticles (Si-NPs) into a carbon matrix is a technique that has been well 
developed; here, the carbonaceous material acts to buffer the volume expansion and improves the electrical conductivity of the Si active materials [13].

As an effective synthetic route for Si-NPs, this study proposes the solution-plasma-mediated synthesis [20-30]. In this process, Si-NPs are directly synthesized from a Si bar electrode via a solution-plasma treatment. Our previous study revealed that the use of a strong acid electrolyte solution was effective for producing Si-NPs without oxidation [31]. In general, the solution plasma technique offers many advantages, such as (1) simple experimental setup, (2) use of readily available precursors, and (3) applicability to mass production. Unfortunately, with respect to the last point, strong acid solution is not applicable on large scale. Furthermore, the performance of LIBs based on Si-NPs synthesized from solution plasma is still unclear. Therefore, in this study, we have optimized the Si-NPs synthesis conditions using mild buffer solutions.

In addition to the Si-NPs synthesis, the fabrication of a composite material consisting of the $\mathrm{Si}-\mathrm{NPs}$ and porous carbon is also important for overcoming the volume-change issue. This study applied a sol-gel solution-combustion synthesis (SCS) approach, which is a highly exothermic and self-sustaining process involving heating a homogeneous solution of aqueous metal salts and fuels such as urea, citric acid, glycine acid, or glycine [32-37]. This method has been applied to synthesize a Sn-NP-embedded porous carbon structure, using nanosized $\mathrm{MgO}$ as the template upon which to construct the porous structure; this material displayed good cycle performance as an LIB anode [38]. Based on this result, a Si-C composite material was synthesized via $\mathrm{MgO}$ template-assisted SCS, in which the starting material was a gel containing the Si-NPs, glycine $\left(\mathrm{C}_{2} \mathrm{H}_{5} \mathrm{O}_{2} \mathrm{~N}\right)$ as the carbon source, and $\mathrm{Mg}\left(\mathrm{NO}_{3}\right)_{2} \cdot 6 \mathrm{H}_{2} \mathrm{O}$ as the template. After the combustion reaction, the generated $\mathrm{MgO}$ was removed from the carbon, leaving the Si-NPs dispersed throughout the porous carbon structure after calcination in $\mathrm{N}_{2}$. The obtained materials were characterized by X-ray diffractometry (XRD) and transmission electron microscopy (TEM). Finally, the electrochemical properties of the product as an LIB anode material were investigated.

\section{Materials and Methods}

Figure 1 shows the experimental setup for producing the Si particles and a schematic diagram for the solution-combustion synthesis of the $\mathrm{Si}-\mathrm{C}$ composite. A B-doped p-type $\mathrm{Si}$ bar with a square cross-sectional width of $5.0 \mathrm{~mm}$ (Shin-Etsu Chemical Co., Ltd., Tokyo, Japan) and electrical resistance of $0.00494-0.00478 \Omega \mathrm{cm}$ was used as the cathode. The upper part of the Si bar was shielded by a quartz glass tube to generate a plasma at the bottom tip of the electrode. A counter electrode was the Pt mesh. A voltage was applied using a direct current power supply. To study the effect of the electrolyte on the generation of the Si-NPs, solutions of $\mathrm{KCl}+\mathrm{H}_{3} \mathrm{BO}_{3}, \mathrm{KH}_{2} \mathrm{PO}_{4}+\mathrm{K}_{2} \mathrm{HPO}_{4}$, and $\mathrm{LiCl}+\mathrm{H}_{3} \mathrm{BO}_{3}$ were used. The electrolyte concentrations and applied voltages are summarized in Table 1. After the synthesis, the products were collected by filtration and then washed several times with deionized water.

Table 1. Summary of experimental conditions and changes in $\mathrm{pH}$ and electrical conductivity for each electrolyte.

\begin{tabular}{|c|c|c|c|c|c|c|c|c|}
\hline \multirow[b]{2}{*}{ Electrolyte } & \multirow[b]{2}{*}{ Voltage (V) } & \multirow[b]{2}{*}{ Current (A) } & \multicolumn{3}{|c|}{ Before } & \multicolumn{3}{|c|}{ After } \\
\hline & & & pH (-) & $\begin{array}{c}\text { Electrical } \\
\text { Conductivity } \\
(\mathrm{mS} / \mathrm{m})\end{array}$ & $\begin{array}{c}\text { Electrolyte } \\
\text { Temperature } \\
\left({ }^{\circ} \mathrm{C}\right)\end{array}$ & pH (-) & $\begin{array}{c}\text { Electrical } \\
\text { Conductivity } \\
(\mathrm{mS} / \mathrm{m})\end{array}$ & $\begin{array}{c}\text { Electrolyte } \\
\text { Temperature } \\
\left({ }^{\circ} \mathrm{C}\right)\end{array}$ \\
\hline $\begin{array}{c}\mathrm{KCl} 0.125 \mathrm{M}+ \\
\mathrm{H}_{3} \mathrm{BO}_{3} 0.125 \mathrm{M} \\
\end{array}$ & 195 & 2.01 & 4.84 & 1509 & 93.4 & - & - & 94.8 \\
\hline $\begin{array}{c}\mathrm{KH}_{2} \mathrm{PO}_{4} 0.249 \mathrm{M}+ \\
\mathrm{K}_{2} \mathrm{HPO}_{4} 0.001 \mathrm{M}\end{array}$ & 189 & 2.46 & 4.54 & 1879 & 92.3 & 4.59 & 1848 & 95.6 \\
\hline $\begin{array}{c}\mathrm{LiCl} 0.2 \mathrm{M}+ \\
\mathrm{H}_{3} \mathrm{BO}_{3} 0.15 \mathrm{M}\end{array}$ & 180 & 1.56 & 5.11 & 1716 & 94.7 & 7.52 & 1670 & 98.7 \\
\hline
\end{tabular}




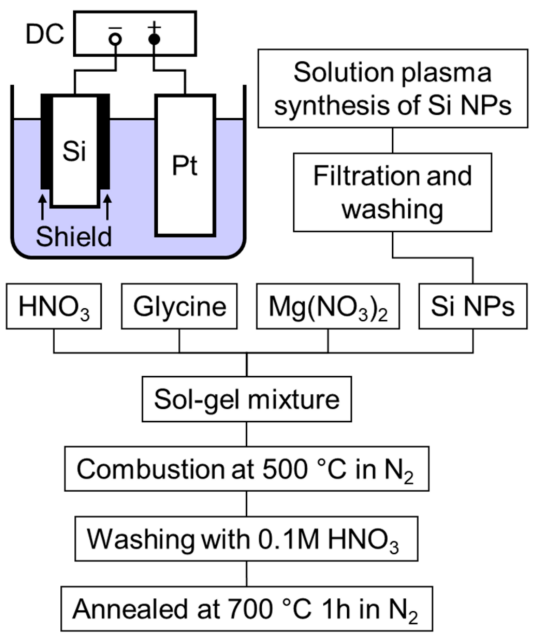

Figure 1. (Color online) Experimental setup for producing Si particles and schematic diagram for the solution combustion synthesis of $\mathrm{Si}-\mathrm{C}$ the composite.

To synthesize the Si-C composite, commercially available $\mathrm{Mg}\left(\mathrm{NO}_{3}\right)_{2} \cdot 6 \mathrm{H}_{2} \mathrm{O}(1.282 \mathrm{~g}, 0.005 \mathrm{M})$ and $\mathrm{C}_{2} \mathrm{H}_{5} \mathrm{O}_{2} \mathrm{~N}(2.252 \mathrm{~g}, 0.03 \mathrm{M})$ were added to $20 \% \mathrm{HNO}_{3}$ solution $(20 \mathrm{~mL})$. After agitation, the Si-NPs (30 mg) synthesized as described above were added to the $\mathrm{HNO}_{3}$ solution and then dispersed with a thin-film spin system high-speed mixer (Filmix Model 30-L, PRIMIX Corp., Osaka, Japan) at $5000 \mathrm{rpm}$ for $15 \mathrm{~min}$. The resulting solution was then dried on a hot plate at $90{ }^{\circ} \mathrm{C}$. The prepared gel was transferred to a furnace for combustion synthesis. The furnace was evacuated to below $100 \mathrm{~Pa}$ and then nitrogen was introduced at $2 \mathrm{~L} / \mathrm{min}$. The annealing temperature was set at $500{ }^{\circ} \mathrm{C}$. Upon reaching 200-300 ${ }^{\circ} \mathrm{C}$, the gel quickly combusted, releasing a large amount of gases. After SCS, the obtained particles were washed sequentially with $0.1 \mathrm{M} \mathrm{HNO}_{3}$ solution and deionized water to remove the $\mathrm{MgO}$ phase. After drying, the sample was calcined at $700{ }^{\circ} \mathrm{C}$ for $1 \mathrm{~h}$ under $\mathrm{N}_{2}$ atmosphere.

The particles obtained at the end of each step were analyzed via XRD (Miniflex600, Rigaku, Tokyo, Japan), employing $\mathrm{Cu} \mathrm{K} \alpha$ radiation $(\lambda=1.5418 \AA)$. The microstructure of the samples was observed using a field-emission scanning electron microscope (SEM; JSM-7001FA, JEOL, Tokyo, Japan), in which the inner structure of the porous particle was observed by the ion-milling technique using a cross-sectional polisher (CP, IB-19510CP, JEOL, Tokyo, Japan ). TEM imaging (JEOL JEM-2010F, Tokyo, Japan) was also performed. Raman spectra of the porous carbon were acquired from a LabRam 1B Raman spectrometer (HORIBA, Kyoto, Japan).

Electrochemical characterization was performed in two-electrode Swagelok-type cells. The working electrode consisted of the active material, conductive carbon (acetylene black), and a polymer binder of sodium carboxymethyl cellulose (CMC) and poly(acrylic acid) (PAA) in a weight ratio of 75:15:5:5. The well-blended solution-based slurry was spread onto copper foil and dried at $60^{\circ} \mathrm{C}$ for $3 \mathrm{~h}$ under vacuum. The dried electrode was punched into a 14-mm-diameter disc with a mass loading of 2-3 mg. A metallic lithium disc (15-mm diameter) was used as the counter and reference electrodes. The cells were assembled in an Ar-filled glove box (UNICO), using a solution of $1 \mathrm{M} \mathrm{LiPF}_{6}$ dissolved in ethylene carbonate $(\mathrm{EC}) /$ dimethyl carbonate $(\mathrm{DMC})(1: 1 \mathrm{v} / \mathrm{v})$ as the electrolyte and a polypropylene membrane as the separator. The cells were galvanostatically cycled from 0.01 to $2.0 \mathrm{~V}$ versus $\mathrm{Li} / \mathrm{Li}^{+}$at $0.5 \mathrm{~A} / \mathrm{g}$ in the constant current mode using a battery charge/discharge system (MSTAT4, Arbin Instruments, College station, TX, USA) at a constant temperature of $25^{\circ} \mathrm{C}$.

\section{Results and Discussion}

The Si-NPs were synthesized using solution plasma generated by contact glow discharge electrolysis (CGDE). Two electrodes consisting of a Si bar and Pt mesh were placed in a glass cell and a direct-current voltage was applied. When the voltage was increased above $1.3 \mathrm{~V}$, the current 
increased linearly in accordance with Ohm's law, corresponding to the occurrence of water electrolysis. Since the electrode surface of $\mathrm{Si}$ is smaller than the Pt mesh, the thermal loss concentrates at the Si anode-solution interface. When a higher voltage is applied, the increased current heats the solution near the Si electrode, and finally, the solution temperature surrounding Si electrode exceeds the boiling point and a gas layer consisting of steam is generated. Once the gas layer is generated, the cathode and solution are no longer in contact and the current is decreased. When the voltage is sufficiently high $(>150 \mathrm{~V})[39,40]$, a discharge with intense light emission begins in the gas layer. The surface of the electrode partially melts to produce nanoparticles, owing to the concentration of the current caused by the electrothermal instability [41,42]. Control parameters for size of Si-NPs are applied voltage and plasma mode. When the plasma mode is kept as a partial plasma region, the particle size decreases with an increase of applied voltage [43,44]. However, the higher applied voltage induces the transition from partial plasma to full plasma region, in which coarse particles are formed under the high excitation temperature. Thus, we have selected the appropriate voltage for each electrolyte, as shown in Table 1.

In our previous study, $\mathrm{K}_{2} \mathrm{CO}_{3}, \mathrm{KNO}_{3}, \mathrm{KCl}, \mathrm{HNO}_{3}$, and $\mathrm{HCl}$ electrolytes were used for Si-NPs synthesis; among these, the acid solutions were effective for producing Si-NPs without oxidation [31]. When the electrolyte was either a strong acid or strong base, the $\mathrm{pH}$ remained constant. The $\mathrm{pH}$ of $\mathrm{KNO}_{3}$ and $\mathrm{KCl}$ increased during electrolysis because of the consumption of negative ions and formation of $\mathrm{OH}^{-}$ions. In principle, the electrolysis of an acidic solution can be described as follows:

$$
2 \mathrm{H}_{2} \mathrm{O}=4 \mathrm{H}^{+}+\mathrm{O}_{2}(\mathrm{~g})+2 \mathrm{e}^{-}
$$

However, the reduction of $\mathrm{Cl}^{-}$ions is favored over the decomposition of $\mathrm{H}_{2} \mathrm{O}$ :

$$
2 \mathrm{Cl}^{-}=\mathrm{Cl}_{2}(\mathrm{~g})+2 \mathrm{e}^{-}
$$

Therefore, the $\mathrm{pH}$ in the neutral solution increases during electrolysis due to the generation of $\mathrm{Cl}_{2}$ gas, and oxidized Si particles are then formed to react with the $\mathrm{OH}^{-}$ions, which produce $\mathrm{Cl}^{-}$ ions instead. At certain hot spots on the electrode surface during the plasma electrolysis, the $\mathrm{Si}^{2+}$ ions were generated, and they combined with $\mathrm{OH}^{-}$to form $\mathrm{SiO}_{2}: \mathrm{Si}^{2+}+2 \mathrm{OH}^{-} \rightarrow \mathrm{Si}(\mathrm{OH})_{2} \rightarrow \mathrm{SiO}_{2}+\mathrm{H}_{2} \mathrm{O}$. Etching of $\mathrm{Si}$ in $\mathrm{KOH}$ and $\mathrm{NaOH}$ was also reported by other research groups [45,46]. Thus, the $\mathrm{pH}$ value of the electrolyte might have affected the product phase. In the case of $\mathrm{KNO}_{3}$ solution as the electrolyte, the reduction of $\mathrm{NO}_{3}{ }^{-}$to $\mathrm{NO}_{2}{ }^{-}$may occur at the cathode electrode [47].

$$
\mathrm{NO}_{3}^{-}+2 \mathrm{e}^{-}+\mathrm{H}_{2} \mathrm{O}=\mathrm{NO}_{2}^{-}+2 \mathrm{OH}^{-}
$$

Previously, we found that the $\mathrm{pH}$ values of $0.1 \mathrm{M} \mathrm{KCl}$ and $\mathrm{KNO}_{3}$ solutions were increased from 6.13 and 6.87 to 8.71 and 9.88, respectively, during the solution-plasma synthesis of Si-NPs [44]. When the electrolyte solution becomes too alkaline, the synthesized Si-NPs tend to be oxidized. In contrast, strong acids such as $\mathrm{HCl}$ and $\mathrm{HNO}_{3}$ are effective for Si-NPs synthesis, but such strong acids are harmful and corrosive. Thus, the use of neutral solutions is attractive because of their safety and non-corrosive natures. This study investigates the non-volatile buffer solutions, $\mathrm{KCl} 0.125 \mathrm{M}$ $+\mathrm{H}_{3} \mathrm{BO}_{3} 0.125 \mathrm{M}, \mathrm{KH}_{2} \mathrm{PO}_{4} 0.249 \mathrm{M}+\mathrm{K}_{2} \mathrm{HPO}_{4} 0.001 \mathrm{M}$, and $\mathrm{LiCl} 0.2 \mathrm{M}+\mathrm{H}_{3} \mathrm{BO}_{3} 0.15 \mathrm{M}$. In the experiments, solution plasma is successfully generated in each electrolyte. As shown in Table 1 , the changes in $\mathrm{pH}$ are smaller compared to the cases of neutral single-electrolyte solutions, suggesting the effectiveness of the buffered systems. The initial solution temperature was over $92{ }^{\circ} \mathrm{C}$ because the pre-warming of the electrolysis was effective for initiate the plasma generation [48]. During Si-NPs production, solution temperature was controlled in the range of $94 \sim 99{ }^{\circ} \mathrm{C}$.

The produced Si-NPs were collected and characterized by XRD, SEM, and TEM. Figure 2 shows the XRD patterns of the synthesized crystalline Si-NPs. generated in the three buffer solutions. Figure $3 a-c$ shows the SEM images of the synthesized Si-NPs. The synthesized particles are almost 
spherical, and some particles have an oval sphere shape. During melting and solidification process, the generated particles forms sphere due to a surface tension. The particle size was measured using low magnification TEM as shown in Figure 4, in which the particle size with over $50 \mathrm{~nm}$ were analyzed using low magnification TEM. In the case of the $\mathrm{KCl}+\mathrm{H}_{3} \mathrm{BO}_{3}$ solution, the particle size of Si particles widely distributed from $50 \mathrm{~nm}$ to over $1 \mu \mathrm{m}$. Although the $\mathrm{KH}_{2} \mathrm{PO}_{4}+\mathrm{K}_{2} \mathrm{HPO}_{4}$ solution produces smaller particles, the $\mathrm{LiCl}+\mathrm{H}_{3} \mathrm{BO}_{3}$ solution is the most effective for producing small Si-NPs. Although the detailed mechanism is still unclear, ions such as $\mathrm{K}^{+}, \mathrm{Na}^{+}$, and $\mathrm{Li}^{+}$are excited in the light-emitting plasma layer [49], and these excited species might affect the generated plasma and local current concentration, resulting in the change in product size. Figure 5 shows high-resolution TEM images of the Si-NPs synthesized in the $\mathrm{LiCl}+\mathrm{H}_{3} \mathrm{BO}_{3}$ solution, in which Si-NPs with diameters of less than $10 \mathrm{~nm}$ can also be observed. From the high-resolution TEM image shown in Figure 4b, small Si-NPs have a single-crystalline structure, in which the obtained d spacing matched to the $\{111\}$ plane of cubic diamond-structured Si.

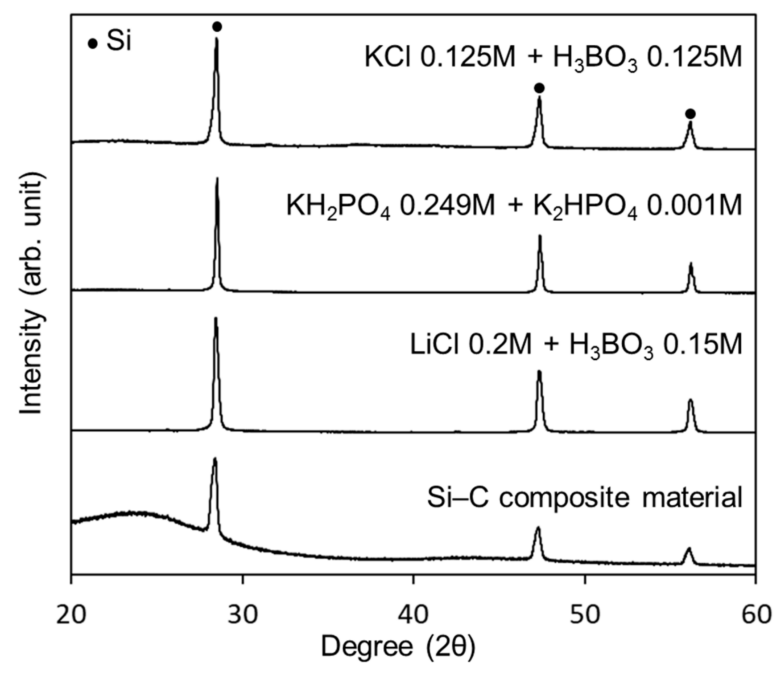

Figure 2. XRD patterns of the synthesized Si-NPs, as well as the Si-C composite prepared from Si-NPs generated in $\mathrm{LiCl}+\mathrm{H}_{3} \mathrm{BO}_{3}$ solution.

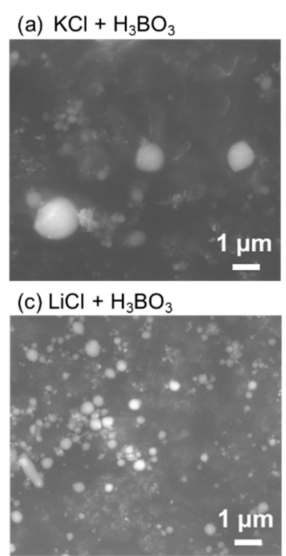

(b) $\mathrm{KH}_{2} \mathrm{PO}_{4}+\mathrm{K}_{2} \mathrm{HPO}_{4}$

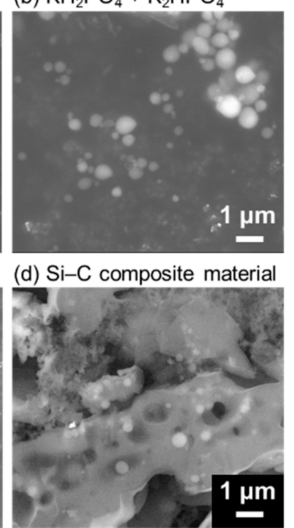

(e) $\mathrm{MgO}$

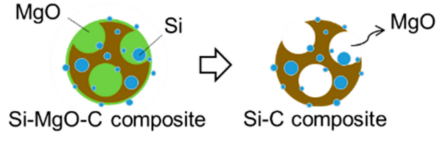

Figure 3. (a-c) SEM images of Si-NPs synthesized in different buffers; and (d) cross-sectional SEM image of $\mathrm{Si}-\mathrm{C}$ composite ( $\mathrm{LiCl}+\mathrm{H}_{3} \mathrm{BO}_{3}$ solution); (e) Illustration of porous Si-C composite material. 


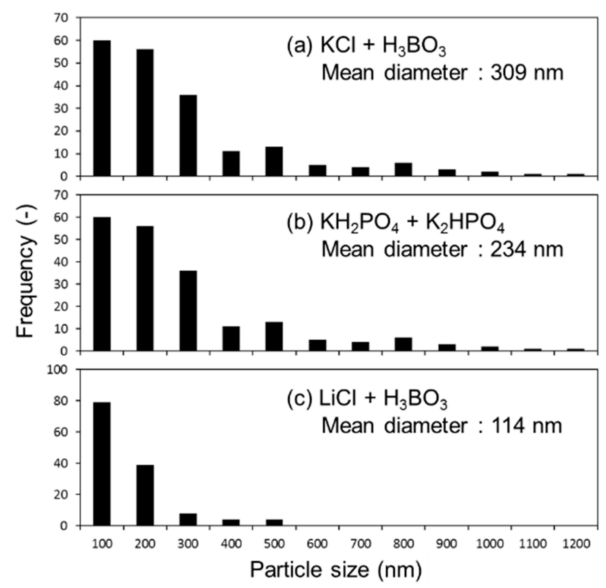

Figure 4. The particle size distribution of Si-NPs, in which the particle sizes with over $50 \mathrm{~nm}$ were analyzed using a low magnification TEM.
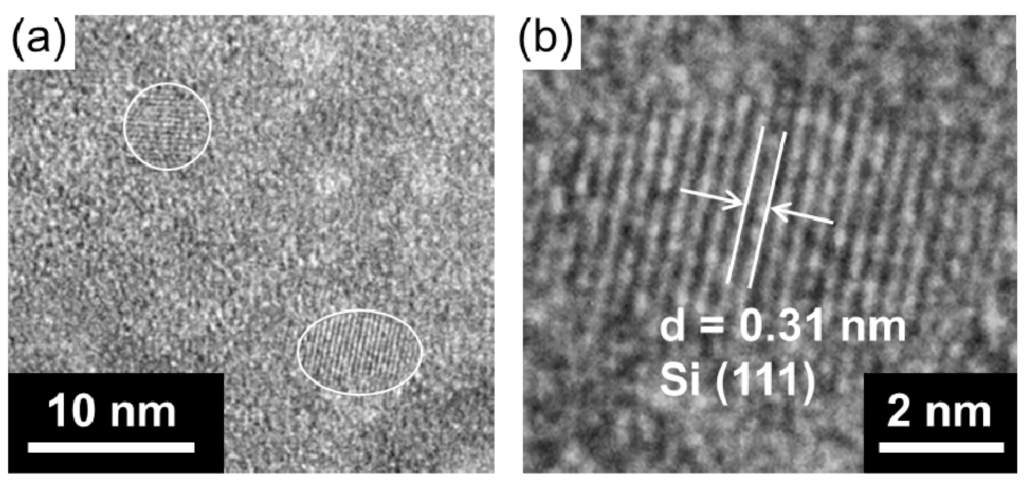

Figure 5. (a) High-resolution TEM image of $\mathrm{Si}-\mathrm{NPs}$ synthesized using $\mathrm{LiCl}+\mathrm{H}_{3} \mathrm{BO}_{3}$ solution. The white circle indicates the Si-NPs; (b) Enlarged image of Si-NPs. The obtained d spacing matched to the $\{111\}$ plane of cubic diamond-structured Si.

For the LIB measurements, composite materials of porous carbon and Si-NPs were synthesized via $\mathrm{MgO}$ template-assisted SCS to accommodate the huge volume expansion of Si-NPs during the lithiation reaction. As indicated in Figure 1, the starting material is a gel containing the Si-NPs, glycine as the carbon source, and $\mathrm{Mg}\left(\mathrm{NO}_{3}\right)_{2} \cdot 6 \mathrm{H}_{2} \mathrm{O}$ as the template. After the combustion reaction, the generated $\mathrm{MgO}$ is removed from the carbon, and the Si-NPs remain dispersed throughout the porous carbon structure after calcination under $\mathrm{N}_{2}$, as shown in the schematic illustration in Figure 3e. This process has been applied to fabricate a composite material of Sn-NPs and carbon, which successfully improved battery properties [37]. Figure 2 shows the XRD pattern of the synthesized Si-C composite. After combustion synthesis, the crystal structure of the $\mathrm{Si}$ is unchanged and a broad peak originating from the carbon structure has appeared. Figure 6 shows the Raman spectrum of the Si-C composite. The peak at around $500 \mathrm{~cm}^{-1}$ corresponds to a silicon band [50,51]. Two strong peaks at around 1350 and $1570 \mathrm{~cm}^{-1}$ are D-band and G-band of carbon, indicating the disordered carbon and ordered graphitic carbon, respectively. The ratios of the intensities of the D-band to G-band, $I_{\mathrm{D}} / I_{\mathrm{G}}$, are higher than 1 for Si-C composite. This indicates that the synthesized porous carbon has disordered carbon structure, rather than highly graphitic structure. It is reported that the generated carbon contains nitrogen after SCS using glycine and nitrate [38,52]. The existence of nitrogen might affect to the crystallinity of the generated carbon. 


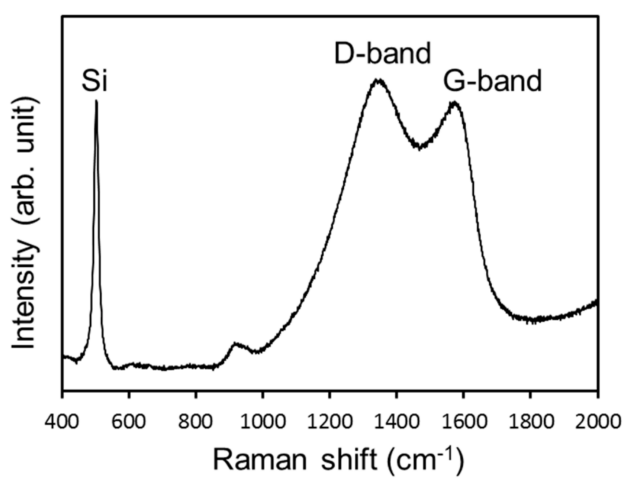

Figure 6. Raman spectrum of the Si-C composite prepared from Si-NPs generated in $\mathrm{LiCl}+\mathrm{H}_{3} \mathrm{BO}_{3}$ solution.

The electrochemical properties of the synthesized composites were investigated using a Li disk as the reference and counter electrodes at a current density of $0.5 \mathrm{~A} / \mathrm{g}$. Figure 7 shows the cyclic performance of the materials synthesized in the different electrolytes. The $\mathrm{Si}-\mathrm{C}$ composite containing the $\mathrm{LiCl}+\mathrm{H}_{3} \mathrm{BO}_{3}$ solution-based Si-NPs shows a higher initial discharge capacity (over $1300 \mathrm{mAh} / \mathrm{g}$ ) compared to the other electrolyte-derived composites, and the capacity gradually decreases with increasing cycle number. This same composite material (using Si-NPs from prepared in $\mathrm{LiCl}+\mathrm{H}_{3} \mathrm{BO}_{3}$ solution) exhibits a higher reversible capacity $(537 \mathrm{mAh} / \mathrm{g})$ after 30 discharge/charge cycles at a current rate of $0.5 \mathrm{~A} / \mathrm{g}$, compared to the $283 \mathrm{mAh} / \mathrm{g}$ observed for the composite prepared with $\mathrm{KCl}+\mathrm{H}_{3} \mathrm{BO}_{3}$ solution-based Si-NPs. Because the theoretical capacity of graphite is $360 \mathrm{mAh} / \mathrm{g}$, these results reveal that the synthesized Si-NPs can function as anode materials. The difference in capacity is mainly due to the particle size of the Si-NPs. When the particle size of the Si-NPs is less than $150 \mathrm{~nm}$ [5], their fracture during cycling can be avoided. Thus, the small Si-NPs produced in the $\mathrm{LiCl}+\mathrm{H}_{3} \mathrm{BO}_{3}$ solution are effective for increasing the capacity. However, the discharge capacity continuously decreases. Because the volume expansion of the Si-NPs during lithiation exceeds $400 \%$, the synthesized porous structure might be insufficient to accommodate this expansion, resulting in the fracture of the carbon electrode. In the case of the Sn-C composite synthesized by the solution-combustion method [38], the synthesized $\mathrm{SnO}_{2}$ nanoparticles are reduced by the surrounding carbon to form a $\mathrm{Sn}$ melt during calcination. This Sn melt moves to the surface of the porous carbon, resulting in the "attachment" of the Sn nanoparticles to the carbon structure to afford excellent battery performance. In the case of the Si-NPs, the solid Si-NPs are "embedded" in the carbon structure, as shown in Figure 3d, which might have induced the pulverization of the composite. A smaller particle size, use of a polymer, and a well-organized porous structure should increase the cycle stability.

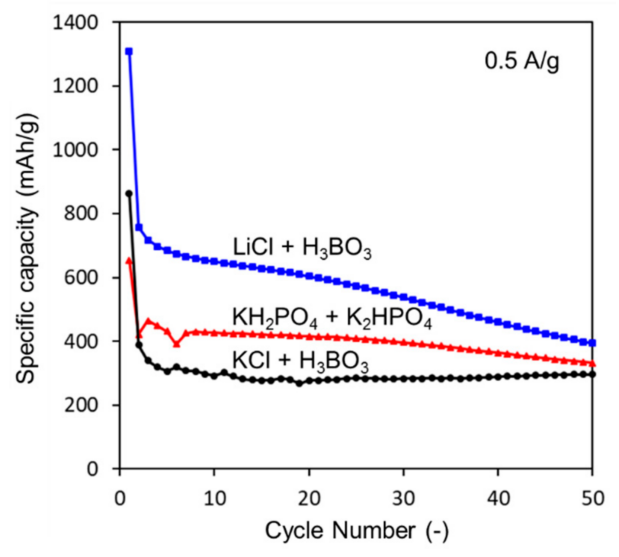

Figure 7. Cycling performance of $\mathrm{Si}-\mathrm{C}$ composite anode materials at $0.5 \mathrm{~A} / \mathrm{g}$ ranging from 0.01 to $2.00 \mathrm{~V}$. 


\section{Conclusions}

In this study, Si nanoparticles (Si-NPs) were synthesized via a facile solution-plasma-mediated synthesis, and composites consisting of Si-NPs and porous carbon were fabricated as the anode materials for lithium-ion batteries. Among several mild buffer solutions investigated, the $\mathrm{LiCl}$ $0.2 \mathrm{M}+\mathrm{H}_{3} \mathrm{BO}_{3} 0.15 \mathrm{M}$ solution effectively produced smaller Si-NPs. These Si-NPs were formed from a solid Si bar via local current concentration during the solution-plasma treatment. High-resolution TEM imaging confirmed the synthesis of Si-NPs with diameters of less than $10 \mathrm{~nm}$. The Si-C composite material was synthesized via $\mathrm{MgO}$ template-assisted solution-combustion synthesis. The composite material obtained from the $\mathrm{LiCl} 0.2 \mathrm{M}+\mathrm{H}_{3} \mathrm{BO}_{3} \quad 0.15 \mathrm{M}$ solution exhibited a reversible capacity of $537 \mathrm{mAh} / \mathrm{g}$ after 30 discharge/charge cycles at a current rate of $0.5 \mathrm{~A} / \mathrm{g}$, as compared to the $283 \mathrm{mAh} / \mathrm{g}$ observed for the $\mathrm{KCl} 0.125 \mathrm{M}+\mathrm{H}_{3} \mathrm{BO}_{3} 0.125 \mathrm{M}$ solution. The increased reversible capacity is mainly due to the decreased particle size of the Si-NPs. These results clearly show the applicability of this facile and environmentally friendly solution-plasma technique for producing Si-NPs as an anode material for LIBs.

Author Contributions: Genki Saito measured the electrochemical performance and wrote the manuscript. Hitoshi Sasaki synthesized the Si nanoparticles. Heishichiro Takahashi and Norihito Sakaguchi contributed to the analysis by electron microscopy. All authors approved the final version of the manuscript.

Acknowledgments: A part of this work was conducted at "Joint-Use Facilities: Laboratory of Nano-Micro Material Analysis" at Hokkaido University, supported by the "Material Analysis and Structure Analysis Open Unit (MASAOU)" and "Nanotechnology Platform" Program of the Ministry of Education, Culture, Sports, Science and Technology (MEXT), Japan. This work was supported by the Iketani Science and Technology Foundation.

Conflicts of Interest: The authors declare no conflict of interest.

\section{References}

1. Obrovac, M.N.; Christensen, L. Structural Changes in Silicon Anodes during Lithium Insertion/Extraction. Electrochem. Solid-State Lett. 2004, 7, A93-A96. [CrossRef]

2. Kasavajjula, U.; Wang, C.; Appleby, A.J. Nano- and bulk-silicon-based insertion anodes for lithium-ion secondary cells. J. Power Sources 2007, 163, 1003-1039. [CrossRef]

3. Zhang, W.-J. A review of the electrochemical performance of alloy anodes for lithium-ion batteries. J. Power Sources 2011, 196, 13-24. [CrossRef]

4. Ozanam, F.; Rosso, M. Silicon as anode material for Li-ion batteries. Mater. Sci. Eng. B 2016, $213,2-11$. [CrossRef]

5. Liu, X.H.; Zhong, L.; Huang, S.; Mao, S.X.; Zhu, T.; Huang, J.Y. Size-Dependent Fracture of Silicon Nanoparticles During Lithiation. ACS Nano 2012, 6, 1522-1531. [CrossRef] [PubMed]

6. Xun, S.; Song, X.; Grass, M.E.; Roseguo, D.K.; Liu, Z.; Battaglia, V.S.; Liu, G. Improved Initial Performance of Si Nanoparticles by Surface Oxide Reduction for Lithium-Ion Battery Application. Electrochem. Solid-State Lett. 2011, 14, A61-A63. [CrossRef]

7. Wu, H.; Zheng, G.; Liu, N.; Carney, T.J.; Yang, Y.; Cui, Y. Engineering Empty Space between Si Nanoparticles for Lithium-Ion Battery Anodes. Nano Lett. 2012, 12, 904-909. [CrossRef] [PubMed]

8. Zuo, X.; Zhu, J.; Müller-Buschbaum, P.; Cheng, Y.-J. Silicon based lithium-ion battery anodes: A chronicle perspective review. Nano Energy 2017, 31, 113-143. [CrossRef]

9. Ikonen, T.; Nissinen, T.; Pohjalainen, E.; Sorsa, O.; Kallio, T.; Lehto, V.P. Electrochemically anodized porous silicon: Towards simple and affordable anode material for Li-ion batteries. Sci. Rep. 2017, 7, 7880. [CrossRef] [PubMed]

10. Gao, P.; Tang, H.; Xing, A.; Bao, Z. Porous silicon from the magnesiothermic reaction as a high-performance anode material for lithium ion battery applications. Electrochim. Acta 2017, 228, 545-552. [CrossRef]

11. Cho, J. Porous Si anode materials for lithium rechargeable batteries. J. Mater. Chem. 2010, 20, 4009-4014. [CrossRef]

12. Chen, Y.; Hu, Y.; Shen, Z.; Chen, R.; He, X.; Zhang, X.; Li, Y.; Wu, K. Hollow core-shell structured silicon@carbon nanoparticles embed in carbon nanofibers as binder-free anodes for lithium-ion batteries. J. Power Sources 2017, 342, 467-475. [CrossRef] 
13. Zhou, M.; Cai, T.; Pu, F.; Chen, H.; Wang, Z.; Zhang, H.; Guan, S. Graphene/Carbon-Coated Si Nanoparticle Hybrids as High-Performance Anode Materials for Li-Ion Batteries. ACS Appl. Mater. Interfaces 2013, 5, 3449-3455. [CrossRef] [PubMed]

14. Gomez-Camer, J.L.; Morales, J.; Sanchez, L. Anchoring Si nanoparticles to carbon nanofibers: An efficient procedure for improving Si performance in Li batteries. J. Mater. Chem. 2011, 21, 811-818. [CrossRef]

15. Tao, H.-C.; Fan, L.-Z.; Mei, Y.; Qu, X. Self-supporting Si/Reduced Graphene Oxide nanocomposite films as anode for lithium ion batteries. Electrochem. Commun. 2011, 13, 1332-1335. [CrossRef]

16. Zhou, M.; Pu, F.; Wang, Z.; Cai, T.; Chen, H.; Zhang, H.; Guan, S. Facile synthesis of novel Si nanoparticles-graphene composites as high-performance anode materials for Li-ion batteries. Phys. Chem. Chem. Phys. 2013, 15, 11394-11401. [CrossRef] [PubMed]

17. Luo, Z.; Xiao, Q.; Lei, G.; Li, Z.; Tang, C. Si nanoparticles/graphene composite membrane for high performance silicon anode in lithium ion batteries. Carbon 2016, 98 (Suppl. C), 373-380. [CrossRef]

18. Zhou, X.; Yin, Y.-X.; Wan, L.-J.; Guo, Y.-G. Facile synthesis of silicon nanoparticles inserted into graphene sheets as improved anode materials for lithium-ion batteries. Chem. Commun. 2012, 48, 2198-2200. [CrossRef] [PubMed]

19. Zhang, T.; Gao, J.; Fu, L.J.; Yang, L.C.; Wu, Y.P.; Wu, H.Q. Natural graphite coated by Si nanoparticles as anode materials for lithium ion batteries. J. Mater. Chem. 2007, 17, 1321-1325. [CrossRef]

20. Saito, G.; Akiyama, T. Nanomaterial synthesis using plasma generation in liquid. J. Nanomater. 2015, 16, 299. [CrossRef]

21. Yatsu, S.; Takahashi, H.; Sasaki, H.; Sakaguchi, N.; Ohkubo, K.; Muramoto, T.; Watanabe, S. Fabrication of Nanoparticles by Electric Discharge Plasma in Liquid. Arch. Metall. Mater. 2013, 58, 425. [CrossRef]

22. Saito, G.; Hosokai, S.; Tsubota, M.; Akiyama, T. Synthesis of copper/copper oxide nanoparticles by solution plasma. J. Appl. Phys. 2011, 110, 023302. [CrossRef]

23. Jiang, B.; Zheng, J.; Qiu, S.; Wu, M.; Zhang, Q.; Yan, Z.; Xue, Q. Review on electrical discharge plasma technology for wastewater remediation. Chem. Eng. J. 2014, 236, 348-368. [CrossRef]

24. Chen, Q.; Li, J.; Li, Y.; Zhang, X.; Yang, S. Plasma-Liquid Interaction: A New Way to Synthesize Nanomaterials. arXiv 2014, arXiv:1404.2515.

25. Švrček, V.; Mariotti, D.; Kondo, M. Microplasma-induced surface engineering of silicon nanocrystals in colloidal dispersion. Appl. Phys. Lett. 2010, 97. [CrossRef]

26. Liu, S.-M.; Kobayashi, M.; Sato, S.; Kimura, K. Synthesis of silicon nanowires and nanoparticles by arc-discharge in water. Chem. Commun. 2005, 4690-4692. [CrossRef] [PubMed]

27. Tokushige, M.; Tsujimura, H.; Nishikiori, T.; Ito, Y. Formation of metallic $\mathrm{Si}$ and $\mathrm{SiC}$ nanoparticles from $\mathrm{SiO}_{2}$ particles by plasma-induced cathodic discharge electrolysis in chloride melt. Electrochim. Acta 2013, 100, 300-303. [CrossRef]

28. Tokushige, M.; Nishikiori, T.; Ito, Y. Plasma-induced cathodic discharge electrolysis to form various metal/alloy nanoparticles. Russ. J. Electrochem. 2010, 46, 619-626. [CrossRef]

29. Lee, H.; Lee, W.-J.; Park, Y.-K.; Ki, S.; Kim, B.-J.; Jung, S.-C. Liquid Phase Plasma Synthesis of Iron Oxide Nanoparticles on Nitrogen-Doped Activated Carbon Resulting in Nanocomposite for Supercapacitor Applications. Nanomaterials 2018, 8, 190. [CrossRef] [PubMed]

30. Show, Y.; Ueno, Y. Formation of Platinum Catalyst on Carbon Black Using an In-Liquid Plasma Method for Fuel Cells. Nanomaterials 2017, 7, 31. [CrossRef] [PubMed]

31. Saito, G.; Sakaguchi, N. Solution plasma synthesis of Si nanoparticles. Nanotechnology 2015, $26,23560$. [CrossRef] [PubMed]

32. Da Conceição, L.; Ribeiro, N.F.P.; Furtado, J.G.M.; Souza, M.M.V.M. Effect of propellant on the combustion synthesized Sr-doped $\mathrm{LaMnO}_{3}$ powders. Ceram. Int. 2009, 35, 1683-1687. [CrossRef]

33. Blennow, P.; Hansen, K.K.; Wallenberg, L.R.; Mogensen, M. Synthesis of Nb-doped $\mathrm{SrTiO}_{3}$ by a modified glycine-nitrate process. J. Eur. Ceram. Soc. 2007, 27, 3609-3612. [CrossRef]

34. Nomura, T.; Zhu, C.; Sheng, N.; Murai, R.; Akiyama, T. Solution combustion synthesis of Brownmillerite-type $\mathrm{Ca}_{2} \mathrm{AlMnO}_{5}$ as an oxygen storage material. J. Alloys Compd. 2015, 646, 900-905. [CrossRef]

35. Zhu, C.; Saito, G.; Akiyama, T. A facile solution combustion synthesis of nanosized amorphous iron oxide incorporated in a carbon matrix for use as a high-performance lithium ion battery anode material. J. Alloys Compd. 2015, 633, 424-429. [CrossRef] 
36. Zhu, C.; Saito, G.; Akiyama, T. A new $\mathrm{CaCO}_{3}$-template method to synthesize nanoporous manganese oxide hollow structures and their transformation to high-performance $\mathrm{LiMn}_{2} \mathrm{O}_{4}$ cathodes for lithium-ion batteries. J. Mater. Chem. A 2013, 1, 7077-7082. [CrossRef]

37. Saito, G.; Nakasugi, Y.; Sakaguchi, N.; Zhu, C.; Akiyama, T. Glycine-nitrate-based solution-combustion synthesis of $\mathrm{SrTiO}_{3}$. J. Alloys Compd. 2015, 652, 496-502. [CrossRef]

38. Saito, G.; Zhu, C.; Han, C.-G.; Sakaguchi, N.; Akiyama, T. Solution combustion synthesis of porous Sn-C composite as anode material for lithium ion batteries. Adv. Powder Technol. 2016, 27, 1730-1737. [CrossRef]

39. Sengupta, S.K.; Singh, R.; Srivastava, A.K. A Study on the Origin of Nonfaradaic Behavior of Anodic Contact Glow Discharge Electrolysis. J. Electrochem. Soc. 1998, 145, 2209-2213. [CrossRef]

40. Yerokhin, A.L.; Nie, X.; Leyland, A.; Matthews, A.; Dowey, S.J. Plasma electrolysis for surface engineering. Surf. Coat. Technol. 1999, 122, 73-93. [CrossRef]

41. Okazaki, K.; Mori, Y.; Hijikata, K.; Ohtake, K. Electrothermal instability in the seeded combustion gas boundary layer near cold electrodes. AIAA J. 1978, 16, 334-339. [CrossRef]

42. Uncles, R.; Nelson, A. Dynamic stabilization of the electrothermal instability. Plasma Phys. 1970, $12,917$. [CrossRef]

43. Saito, G.; Hosokai, S.; Akiyama, T.; Yoshida, S.; Yatsu, S.; Watanabe, S. Size-Controlled Ni Nanoparticles Formation by Solution Glow Discharge. J. Phys. Soc. Jpn. 2010, 79, 083501. [CrossRef]

44. Saito, G.; Hosokai, S.; Tsubota, M.; Akiyama, T. Nickel nanoparticles formation from solution plasma using edge-shielded electrode. Plasma Chem. Plasma Process. 2011, 31, 719-728. [CrossRef]

45. Seidel, H.; Csepregi, L.; Heuberger, A.; Baumgärtel, H. Anisotropic Etching of Crystalline Silicon in Alkaline Solutions: I. Orientation Dependence and Behavior of Passivation Layers. J. Electrochem. Soc. 1990, 137, 3612-3626. [CrossRef]

46. Glembocki, O.J.; Stahlbush, R.E.; Tomkiewicz, M. Bias-Dependent Etching of Silicon in Aqueous KOH. J. Electrochem. Soc. 1985, 132, 145-151. [CrossRef]

47. Polatides, C.; Dortsiou, M.; Kyriacou, G. Electrochemical removal of nitrate ion from aqueous solution by pulsing potential electrolysis. Electrochim. Acta 2005, 50, 5237-5241. [CrossRef]

48. Saito, G.; Nakasugi, Y.; Akiyama, T. Generation of solution plasma over a large electrode surface area. J. Appl. Phys. 2015, 118, 023303. [CrossRef]

49. Saito, G.; Nakasugi, Y.; Akiyama, T. Excitation temperature of a solution plasma during nanoparticle synthesis. J. Appl. Phys. 2014, 116. [CrossRef]

50. Reichert, F.; Pérez-Mas, A.M.; Barreda, D.; Blanco, C.; Santamaria, R.; Kuttner, C.; Fery, A.; Langhof, N.; Krenkel, W. Influence of the carbonization temperature on the mechanical properties of thermoplastic polymer derived C/C-SiC composites. J. Eur. Ceram. Soc. 2017, 37, 523-529. [CrossRef]

51. Nanda, J.; Datta, M.K.; Remillard, J.T.; O’Neill, A.; Kumta, P.N. In situ Raman microscopy during discharge of a high capacity silicon-carbon composite Li-ion battery negative electrode. Electrochem. Commun. 2009, 11, 235-237. [CrossRef]

52. Zhu, C.; Han, C.-G.; Saito, G.; Akiyama, T. MnO nanocrystals incorporated in a N-containing carbon matrix for Li ion battery anodes. RSC Adv. 2016, 6, 30445-30453. [CrossRef]

(C) 2018 by the authors. Licensee MDPI, Basel, Switzerland. This article is an open access article distributed under the terms and conditions of the Creative Commons Attribution (CC BY) license (http:/ / creativecommons.org/licenses/by/4.0/). 